\title{
Overexpression of BCL-2, BCL-X, and BAX in Primary Central Nervous System Lymphomas that Occur in Immunosuppressed Patients
}

Sophie Camilleri-Broët, M.D., Philippe Camparo, M.D., Karima Mokhtari, M.D., Khé Hoang Xuan, M.D., Antoine Martin, M.D., Michel Arborio, M.D., Jean-Jacques Hauw, M.D., Martine Raphaël, M.D., Ph.D. Services d'Anatomie Pathologique, Hôtel Dieu (SC-B), de Neuropathologie R. Escourolle, Groupe hospitalier Pitié Salpêtrière (SC-B, KM, J-JH), d'Anatomie Pathologique, Hôpital du Val de Grâce (PC, MA), de Neurologie, Groupe hospitalier Pitié Salpêtrière (KHX), Paris et d'Anatomie Pathologique (AM) et d'Hématologie biologique (MR), Hôpital Avicenne, Bobigny, France

In contrast to primary central nervous system lymphomas (PCNSLs) that occur in immunocompetent patients, most of those that occur in immunosuppressed patients are associated with Epstein-Barr virus (EBV). BCL-2-related proteins either block or promote cell death, forming homo- or heterodimers with each other. LMP-1, EBV latent protein, has been shown to upregulate BCL-2 and BCL-XL. This observation suggests that these proteins may be involved in the transformation process of EBVinfected cells.

Twenty-three cases of PCNSLs were studied: 12 of the patients were immunosuppressed, and 11 were immunocompetent. For all cases, we collected clinical information, histologic data, and immunophenotype and tested for the presence of EBV (EBER-1, LMP-1). Apoptosis was assessed by the TdTmediated dUTP-biotin nick-end labeling method and quantified by image analysis. In three cases, electron microscopy was performed. The BCL-2 family proteins (BCL-2, BCL-X, MCL1, and BAX) and p53 expression were studied by immunohistochemistry on paraffin slides.

All cases were classified as diffuse large B-cell lymphomas. PCNSLs in immunosuppressed patients were characterized by EBV association, necrosis, important gliosis, and numerous macrophages. There was no significant difference between the two groups regarding the TdT-mediated dUTP-biotin nick-end labeling staining $(P=.08)$. In contrast, PCNSLs in immunosuppressed patients were shown to express high levels of BCL-2, BCL-X, and BAX in

Copyright (C) 2000 by The United States and Canadian Academy of Pathology, Inc.

VOL. 13, NO. 2, P. 158, 2000 Printed in the U.S.A.

Date of acceptance: August 13, 1999.

Address reprint requests to: Dr. S. Camilleri-Broët, M.D., Service d'Anatomie Pathologique, Hôtel Dieu, 1 place du parvis Notre Dame, 75181 Paris, France; fax: (33) 0142348641. more than $80 \%$ of tumor cells in 7,10 , and 11 cases, respectively. In immunocompetent patients, only one case showed a high level of BCL-2 expression in more than $80 \%$ of the cells, whereas BCL-X and BAX were overexpressed in two cases. These differences are significant $(P<.05)$. In contrast, there was no significant difference between the two groups in MCL-1 expression. Besides EBV association and necrosis, PCNSLs related to immunosuppression are characterized by an overexpression of BCL-2-related proteins, without dramatically modifying their susceptibility for apoptosis.

KEY WORDS: AIDS, BCL-2, Central nervous system, EBV, Lymphoma.

Mod Pathol 2000;13(2):158-165

Immunosuppressed and immunocompetent patients exhibit different features in primary central nervous system lymphomas (PCNSLs). PCNSLs are mostly large B-cell lymphomas; those related to immunosuppression often have immunoblastic features (1). In contrast, most PCNSLs that occur in immunocompetent patients show a centroblastic polymorphic feature. Epstein-Barr virus (EBV) has been shown to be associated with nearly all AIDSrelated PCNSLs $(2,3)$, whereas it has been described only rarely in those that occur in immunocompetent patients $(4,5)$. This difference in EBV status in PCNSLs allows us to study morphologic and immunohistochemical features that could be related to EBV.

Mitochondrial BCL-2 oncoprotein has been shown to be capable of blocking apoptosis (6). Because this protein efficiently blocks in different models of apoptosis, it has been suggested that it acts in a final common pathway. Recently, several proteins (BCL-X, BAX, MCL-1, A1, BAK, BAD) that share homology with BCL-2 have been described 
(BCL-2 family). They have been shown to interact with each other, forming homo- or heterodimers and either to promote (BAX, BCL-XS, BAK, BAD) or to block (BCL-2, BCL-XL, MCL-1, A1) cell death, depending on their relative quantity $(7,8)$.

The relationships between EBV proteins and those related to BCL-2 remain unclear. $\mathrm{Bcl}-2$ gene transactivation by the viral protein LMP1 has been described in vitro $(9,10)$. In AIDS-related PCNSLs, we have found a correlation between the expression of both LMP1 and BCL-2 (11), which has been confirmed in systemic lymphomas (12). However, the lack of a consistent relationship between LMP1 and BCL-2 expression in human pathologic models could be linked with a possible role of other members of the BCL-2 family. LMP1 has been described to upregulate BCL-X and MCL-1 $(12,13)$.

We report our studies on the expression of BCL-2 family proteins and their effect on apoptosis in two groups of PCNSLs, with opposite EBV status. Although there was no significant difference in the rate of apoptosis, proteins of the BCL-2 family (BCL-2, BCL-X, and BAX) were overexpressed in PCNSLs that occurred in immunosuppressed patients.

\section{MATERIALS AND METHODS}

\section{Patients and Material}

Twenty-three PCNSLs were studied: 12 in immunosuppressed patients (11 patients with AIDS and 1 renal transplant recipient) and 11 in immunocompetent patients. All cerebral samples were obtained from biopsy. The following clinical information was collected for each patient: sex, age, cerebral localization, number of tumors, corticoid treatment before biopsy, and type of biopsy (surgical, stereotaxic). In all cases, hematoxylin-eosin and Giemsa stainings were performed after $4 \%$ formaldehyde fixation and paraffin embedding.

Lymphomas were classified according to the Revised European American Lymphoma classification (14). Necrosis and presence of vascular thrombosis were searched for on hematoxylin-eosin-stained sections. Importance of astrogliosis and macrophage density was assessed as follows: no or few reactive astrocytes/macrophages versus marked astrogliosis or macrophage accumulation (easily seen using a $25 \times$ objective). The number of CD3-positive reactive lymphocytes allowed a classification into two groups: CD3+ lymphocytes representing more or less than $50 \%$ of the whole lymphoid population.

\section{Detection of Epstein-Barr Virus}

In all cases, EBV was detected by in situ hybridization on paraffin sections, using a fluorescein iso- thiocyanate-labeled oligonucleotide complementary to small nuclear EBV encoded RNA1 (EBER1; Dakoppatts, Glostrup, Denmark). An alkaline phosphatase/anti-alkaline phosphatase mouse system was used for detection. LMP1 (Table 1) was detected on paraffin sections, using a standard avidin-biotin-peroxidase method and microwave pretreatment.

EBER and LMP1 positivity were scored semiquantitatively as previously described (15): $0=$ no positive cell, 1 = scattered positive cells in a low power field using a $10 \times$ objective, $2=$ few positive cells per medium power field using a $25 \times$ objective, $3=$ positive cells easily seen in each medium power field, $4=$ many positive cells in each medium power field.

\section{Apoptosis}

Apoptosis was assessed in 21 cases by TdTmediated dUTP-biotin nick-end labeling (TUNEL). Deparaffinized and rehydrated sections were treated with proteinase $\mathrm{K}(0.5 \mu \mathrm{g} / \mathrm{mL})$ for $10 \mathrm{~min}$, then incubated with Caco-cobalt Bio-11dUTP and $\mathrm{TdT}$ at $37^{\circ} \mathrm{C}$ for $60 \mathrm{~min}$. After being washed and endogenous alkaline phosphatase activity was inhibited, sections were incubated with streptavidin/ alkaline phosphatase (1/1000 dilution) for $30 \mathrm{~min}$ at room temperature. They were washed, and revelation was performed with 5-bromo-4-chloro-3-indolyl-phosphatase/Nitroblue tetrazolium for 30 min before being counterstained. We assessed TUNEL positivity by image analysis. A LEITZ DMR (Leica, Heerbrugg, Switzerland) microscope was used with a $40 \times$ objective, operating with a $3 C C D$ Color Video Camera (DXC.93OP, Sony, Japan). Analysis was performed using the ANALYSIS software (SIS Soft Imaging Software Corp., Reutlingen, Germany). For each case, we analyzed three high power fields ( $40 \times$ objective), avoiding the vicinity of necrosis. There were significant areas of necrosis in some of the immunosuppressed group of patients. In two cases, this limited the analysis to one high power field and in four cases limited it to two

TABLE 1. Panel of Antibodies Used for Immunohistochemistry on Paraffin Sections

\begin{tabular}{llll}
\hline Specificity & \multicolumn{1}{c}{ Clone } & Dilution & \multicolumn{1}{c}{ Source } \\
\hline CD20 & L26 & $1 / 1000$ & Dakopatts $^{a}$ \\
CD3 & Polyclonal & $1 / 1000$ & Dakopatts $^{a}$ \\
LMP1 & CS1-4 & $1 / 50$ & Dakopatts $^{a}$ \\
p53 & DO-1 & Prediluted & Immunotech $^{b}$ \\
BCL-2 & 124 & Prediluted & Dakopatts $^{a}$ \\
BCL-X & Polyclonal & $1 / 800$ & Pharmingen $^{c}$ \\
MCL-1 & Polyclonal & $1 / 800$ & Pharmingen $^{c}$ \\
BAX & Polyclonal & $1 / 800$ & Pharmingen $^{c}$ \\
\hline
\end{tabular}

\footnotetext{
${ }^{a}$ Glostrup, Denmark

${ }^{b}$ Luminy, France

${ }^{c}$ San Diego, CA
} 
high power fields. Results were expressed as a percentage of positive surface.

For the 12 immunosuppressed patients, part of the biopsies were fixed in glutaraldehyde and a semi-thin $0.5 \mu \mathrm{m}$ section stained by Toluidine blue was studied. In three cases, the semi-thin section showed adjacent necrosis, so ultrathin sections were stained with uranyl acetate and examined for apoptotic changes and lysis features using a JEOL 100CX2 transmission electron microscope operating at $80 \mathrm{kV}$.

\section{Immunohistochemical Analysis}

Avidin-biotin-peroxidase method was performed on paraffin sections, using a commercially available kit (Vectastain; ABC Vector Laboratories, Burlingame, $\mathrm{CA}$ ) and the monoclonal antibodies (B- and T-cell markers, LMP1, p53, BCL-2 family) as detailed in Table 1. Briefly, tissue sections were deparaffinized, subjected to microwave treatment (three times for $5 \mathrm{~min}$ ), then incubated in $3 \% \mathrm{H}_{2} \mathrm{O}_{2}$ in $70 \%$ methanol for $20 \mathrm{~min}$ and preblocked with bovine serum albumin for $30 \mathrm{~min}$ before incubation with the primary antibody. The complex was visualized with diaminobenzidine, and the nuclei were counterstained with hematoxylin.

For p53 protein, a highly expressing p53 colon carcinoma section was used as a positive control and expression was assessed as follows: 0 when fewer than $10 \%$ of tumor cells were positive, + when 10 to $30 \%$ of positive cells were seen, ++ when more than $30 \%$ of the cells were positive.

For BCL-2-related proteins, mAbs were incubated overnight at room temperature, and normal kidney tissue and reactive lymph nodes were used as positive controls. All of the series was performed on the same day. Two different experiments were done for BCL-X, BAX, and MCL-1. Expression was considered as follows: $0=$ no expression, $+=$ faint expression or in fewer than $80 \%$ of tumor cells, ++ $=$ strong expression in more than $80 \%$ of tumor cells.

\section{Statistical Analysis}

Comparison between the two groups for histologic and immunohistochemical features was tested using the Fisher's exact test. For assessing TUNEL positivity, the Wilcoxon test was used. $P<$ .05 was considered significant.

\section{RESULTS}

\section{Clinical Findings}

The immunosuppressed patients predominantly were young men. For both groups, tumors were primarily supratentorial. Most patients received corticoid treatment a few days before biopsy. All 11 immunocompetent patients received corticoid treatment before biopsy. Of these, five received it for more than 1 week. Eleven of the immunosuppressed patients also received corticoid treatment. Seven of those received one bolus on the day before biopsy (Table 2).

\section{Histopathologic Findings}

All PCNSLs of immunocompetent patients were classified as diffuse large B-cell lymphomas according to the Revised European American Lymphoma classification (14), showing in eight cases features corresponding to the so-called centroblastic polymorphic lymphomas, according to the Kiel updated classification (16). In immunosuppressed patients, all cases were classified as diffuse large B-cell lymphomas; six cases showed immunoblastic morphology with plasmacytic features.

In tumors that occurred in immunosuppressed patients, we found necrosis in nine cases (Fig. 1), reactive astrogliosis in eight cases, and numerous foamy macrophages in seven cases (Table 3 ). These observations were significantly higher than in the immunocompetent patients, in which no necrosis was seen (Fig. 2). Vascular thrombosis was found in six immunosuppressed patients and in one immunocompetent patient $(P=.068)$. We looked for a possible linkage between corticoid treatment (presence versus absence) and the following features: necrosis, vascular thrombosis, and gliosis. There was no significant difference $(P>.05)$.

\section{Epstein-Barr Virus}

No PCNSL of an immunocompetent patient was associated with EBV, as shown by in situ hybridization (EBER1) and LMP1 immunohistochemistry. In contrast, all 12 tumors in the immunosuppressed

TABLE 2. Clinical and Histologic Features

\begin{tabular}{lcc}
\hline Clinical Features & $\begin{array}{c}\text { Immunocompetent } \\
\text { Patients }(N=1)\end{array}$ & $\begin{array}{c}\text { Immunosuppressed } \\
\text { Patients }(N=12)\end{array}$ \\
\hline Sex & $3(27 \%)$ & $11(92 \%)$ \\
$\quad$ Male & $8(73 \%)$ & $1(8 \%)$ \\
$\quad$ Female & $59(30-80)$ & $39(24-59)$ \\
Mean age (range) & & \\
Cerebral localization & $9(82 \%)$ & $11(92 \%)$ \\
$\quad$ Supratentorial & $1(9 \%)$ & 0 \\
$\quad$ Infratentorial & $1(9 \%)$ & $1(8 \%)$ \\
$\quad$ Both & $5(45 \%)$ & $7(58 \%)$ \\
Number of tumors & $6(55 \%)$ & $5(42 \%)$ \\
$\quad$ Unifocal & $3(27 \%)$ & $1(8 \%)$ \\
$\quad$ Multifocal & $3(27 \%)$ & $7(58 \%)$ \\
Corticoid treatment & $5(46 \%)$ & $4(34 \%)$ \\
$\quad$ No treatment & & \\
$<1$ week & & 0 \\
$\geq 1$ week & $3(27 \%)$ & 12 \\
Type of biopsy & $8(73 \%)$ & \\
$\quad$ Surgical & & \\
Stereotaxic & &
\end{tabular}




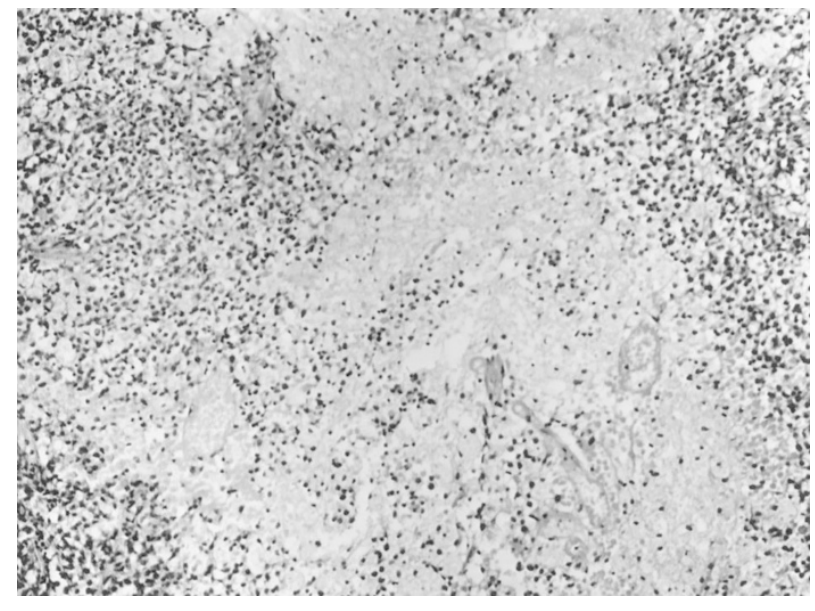

FIGURE 1. Area of necrosis in a case of primary central nervous system lymphoma in an immunosuppressed patient.

TABLE 3. Histologic Features

\begin{tabular}{lccc}
\hline $\begin{array}{c}\text { Immuno- } \\
\text { Characteristics }\end{array}$ & $\begin{array}{c}\text { Immuno- } \\
\text { competent } \\
\text { Patients } \\
(N=11)\end{array}$ & $\begin{array}{c}\text { suppressed } \\
\text { Patients } \\
(N=12)\end{array}$ & $\begin{array}{c}\text { p (Fisher's } \\
\text { exact test) }\end{array}$ \\
\hline Necrosis & 11 & $3(25 \%)$ & $<.001$ \\
Absence & 0 & $9(75 \%)$ & \\
Presence & $10(91 \%)$ & $6(50 \%)$ & NS $(0.068)$ \\
Vascular thrombosis & $1(9 \%)$ & $6(50 \%)$ & \\
Absence & $9(82 \%)$ & $4(33 \%)$ & 0.03 \\
Presence & $2(18 \%)$ & $8(67 \%)$ & \\
Astrogliosis & $10(91 \%)$ & $5(42 \%)$ & 0.03 \\
Scattered & $1(9 \%)$ & $7(58 \%)$ & \\
Numerous & & & \\
Macrophages & $10(91 \%)$ & $11(92 \%)$ & NS \\
Scattered & $1(9 \%)$ & $1(8 \%)$ & \\
Numerous & & & \\
CD3+ lymphocytes & & & \\
$\quad<50 \%$ & & &
\end{tabular}

patients were associated with EBV. Eleven showed a strong nuclear positivity with the EBER1 in situ hybridization, and LMP1 was expressed in 11 cases (Table 4). One case (Patient 23) showed large sheets of necrosis, representing more than half of the sample, and was considered as negative by in situ hybridization, whereas it expressed LMP1.

\section{Apoptosis}

Mean percentages of positive surface with TUNEL (Fig. 3) studied by image analysis were $0.76 \%( \pm 0.33)$ and $0.89 \%( \pm 0.52)$ for immunosuppressed and immunocompetent patients, respectively. Although the rate of apoptosis was slightly higher in immunocompetent patients than in immunosuppressed patients, this difference was not significant $(P=.08)$.

In the three cases studied by electron microscopy, three main features were found. Most of the cells showed morphologic changes of lysis ("necrosis") characterized by marginal clumping of loosely

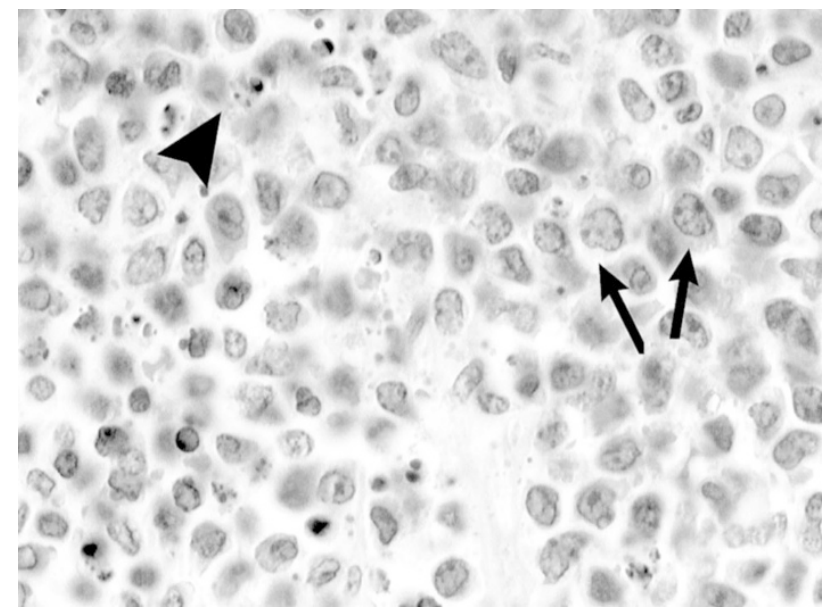

FIGURE 2. Primary central nervous system lymphoma in an immunocompetent patient $(100 \times)$. Most tumor cells are centroblasts (arrows). Apoptotic bodies are scattered among tumor cells (arrowhead).

textured nuclear chromatin and swollen cytoplasm. A minority of cells showed patches of condensed chromatin in a clear cytoplasm, a feature considered "secondary necrosis" (17), whereas a few others exhibited chromatin condensation and margination with cytoplasmic condensation, considered the morphologic hallmark of apoptosis.

\section{Immunohistochemical Study}

All cases were of B-cell lineage tumor cells expressing a high level of CD20 at their membrane. A variable number of reactive lymphocytes, highly expressing CD3 in their cytoplasm, were found scattered between tumor cells or around the perivascular space (Tables 4 and 5). Only two cases were found to have numerous CD3-positive reactive cells, representing the majority of lymphoid cells (Table 3 ).

The p53 protein was expressed in tumors of four immunocompetent patients and four immunosuppressed patients. Among them, only two immunocompetent patients showed p53 expression in more than $30 \%$ of the tumor cells.

BCL-2 was expressed in the cytoplasm of tumor cells in 10 cases of PCNSLs in immunosuppressed patients and in 5 cases of immunocompetent patients $(P=.09)$. BCL-2 was overexpressed in more than $80 \%$ of tumor cells $(++)$ in seven immunosuppressed patients and one immunocompetent patient. This difference was significant $(P=.03)$. BCL-X was strongly expressed $(++)$ in 10 immunosuppressed patients and 2 immunocompetent patients $(P=.003)$. MCL-1 expression was found in 10 immunocompetent patients and all immunosuppressed patients, without significant difference when analyzing cases with overexpression $(++)$. BAX, a dominant inhibitor of BCL-2, was expressed 


\begin{tabular}{|c|c|c|c|c|c|c|c|}
\hline Cases & BCL-2 & BCL-X & MCL-1 & BAX & p53 & EBER & LMP1 \\
\hline \multicolumn{8}{|c|}{ Immunocompetent patients } \\
\hline 1 & 0 & + & ++ & + & 0 & 0 & 0 \\
\hline 2 & 0 & 0 & ++ & 0 & 0 & 0 & 0 \\
\hline 3 & + & + & + & + & 0 & 0 & 0 \\
\hline 4 & 0 & ++ & ++ & + & 0 & 0 & 0 \\
\hline 5 & + & + & ++ & + & 0 & 0 & 0 \\
\hline 6 & ++ & ++ & ++ & + & + & 0 & 0 \\
\hline 7 & 0 & + & 0 & + & ++ & 0 & 0 \\
\hline 8 & + & + & ++ & ++ & + & 0 & 0 \\
\hline 9 & 0 & + & + & ++ & ++ & 0 & 0 \\
\hline 10 & + & + & + & + & 0 & 0 & 0 \\
\hline 11 & 0 & 0 & + & + & 0 & 0 & 0 \\
\hline$N(11)$ & 5 & 9 & 10 & 10 & 4 & 0 & 0 \\
\hline \multicolumn{8}{|c|}{ Immunosuppressed patients } \\
\hline 12 & ++ & ++ & ++ & ++ & 0 & 3 & 4 \\
\hline 13 & 0 & ++ & ++ & ++ & 0 & 3 & 3 \\
\hline 14 & + & + & + & ++ & 0 & 3 & 2 \\
\hline 15 & ++ & ++ & ++ & ++ & + & 1 & 3 \\
\hline 16 & ++ & ++ & + & ++ & + & 3 & 2 \\
\hline 17 & 0 & + & ++ & ++ & 0 & 1 & 4 \\
\hline 18 & ++ & ++ & ++ & ++ & + & 2 & 1 \\
\hline 19 & + & ++ & ++ & ++ & 0 & 2 & 0 \\
\hline 20 & + & ++ & ++ & ++ & 0 & 3 & 3 \\
\hline 21 & ++ & ++ & ++ & + & 0 & 3 & 3 \\
\hline 22 & ++ & ++ & ++ & ++ & 0 & 2 & 4 \\
\hline 23 & ++ & ++ & ++ & ++ & + & 0 & 2 \\
\hline$N(12)$ & 10 & 12 & 12 & 12 & 4 & 11 & 11 \\
\hline
\end{tabular}

BCL-2-related proteins were considered as follows: 0 , no expression; + , expression of less than $80 \%$ of tumor cells or faint expression; ++ , strong expression of more than $80 \%$ of cells. The p53 expression was assessed as follows: $0,<10 \%$ of positive cells;,+ 10 to $30 \%$ positive cells;,$++>30 \%$ positive cells. EBER and LMP1 were assessed as follows: 0 , no positive cell; 1 , scattered positive cells in a low power field (10×); 2, few positive cells per medium power field $(25 \times)$; 3 , positive cells easily seen; 4 , many positive cells in each medium power field.

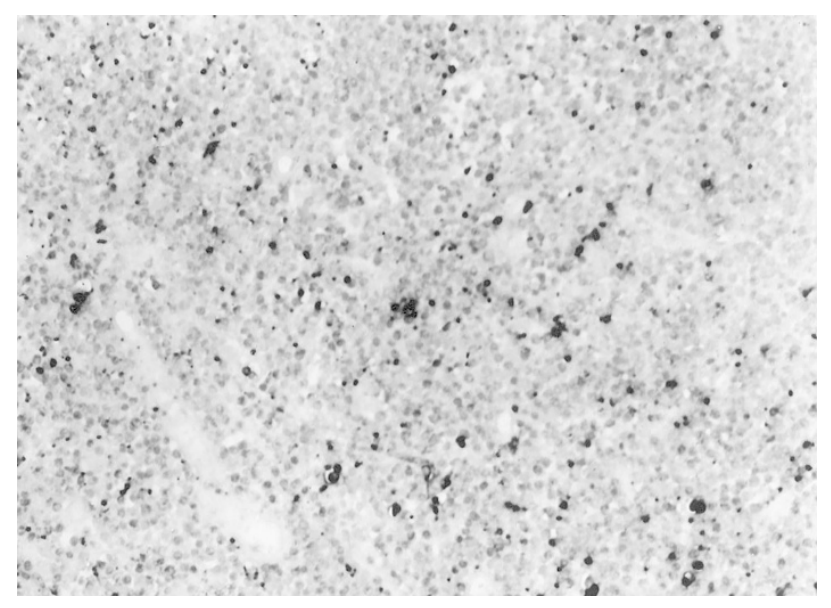

FIGURE 3. TdT-mediated dUTP-biotin nick-end labeling method. Numerous positive nuclei are observed in a case of primary central nervous system lymphoma occurring in an immunocompetent patient.

in all cases but one with a variable intensity. It is surprising that BAX was overexpressed $(++)$ in 11 PCNSLs related to immunosuppression, often showing strong cytoplasmic positivity (Fig. $4 \mathrm{~b}$ compared with Fig. 4a), whereas it was overexpressed in only 2 immunocompetent PCNSLs $(P<.001)$.

\section{DISCUSSION}

The expression of BCL-2-related proteins was studied in two groups of PCNSLs, that were either
TABLE 5. Comparison between the Two Groups for Immunohistochemical Features and Apoptosis

\begin{tabular}{lccc}
\hline & $\begin{array}{c}\text { Immuno- } \\
\text { competent } \\
\text { Patients } \\
(N=11)\end{array}$ & $\begin{array}{c}\text { Immuno- } \\
\text { suppressed } \\
\text { Patients } \\
(N=12)\end{array}$ & $\mathrm{p}$ \\
\hline BCL-2 (++ vs 0,+) & $1(9 \%)$ & $7(58 \%)$ & $0.03^{a}$ \\
BCL-X (++ vs 0,+) & $2(18 \%)$ & $10(83 \%)$ & $0.003^{a}$ \\
MCL-1 (++ vs 0,+) & $6(55 \%)$ & $10(83 \%)$ & $\mathrm{NS}^{a}$ \\
BAX (++ vs 0,+) & $2(18 \%)$ & $11(92 \%)$ & $<.001^{a}$ \\
TUNEL & $0.89 \%( \pm 0.52)$ & $0.76 \%( \pm 0.33)$ & $\mathrm{NS}(0.08)^{b}$ \\
\hline
\end{tabular}

BCL-2 family proteins were considered as overexpressed when more than $80 \%$ of tumor cells were strongly positive $(++)$.

NS, not significant.

${ }^{a}$ Fisher's exact test was used.

${ }^{b}$ Wilcoxon test was used.

related or unrelated to immunosuppression. The first group (11 cases) consisted of PCNSLs that occurred in immunocompetent patients. Although their frequency is increasing (18), this is a relatively rare disease that occurs in patients during their fifth or sixth decade. They usually are diffuse large B-cell non-Hodgkin's lymphomas and are not associated with EBV (4). The second group consisted of 12 PCNSLs in immunosuppressed patients. Eleven were AIDS related, and one was a transplant recipient. As described previously $(2,3)$, these lymphomas were associated with EBV. Because of these distinct characteristics, this model seems suited for analyzing features and expression of proteins that could be related to EBV. 


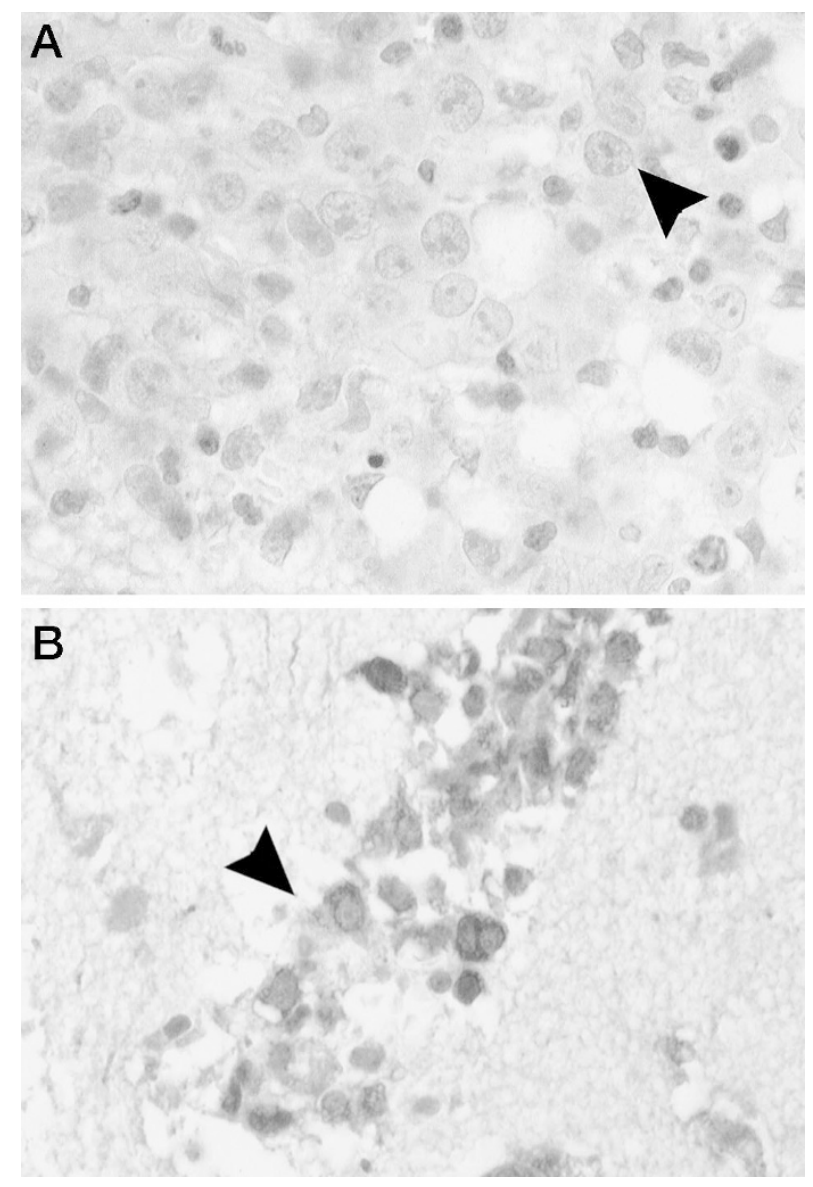

FIGURE 4. A, BAX immunohistochemistry (high magnification) of an immunocompetent patient without overexpression. B, BAX immunohistochemistry (high magnification) of an immunosuppressed patient, showing a strong cytoplasmic overexpression.

The young age and male predominance in the group of PCNSLs related to immunosuppression is probably related to risk factors usually associated with HIV infection. We chose to analyze only cerebral biopsies to avoid postmortem artifacts. However, biopsies allowed us to analyze only part of the tumor. We collected information concerning corticoid treatment before biopsy, which could be considered a confusing factor in the study of cell death and the expression of proteins involved in the control of apoptosis. In both groups, most patients underwent a corticoid treatment of variable duration. We found no linkage between corticoid treatment and necrosis, vascular thrombosis, or astrogliosis. These results suggest that corticoid treatment is not a major confusing factor in the study of histologic features.

A majority of cases related to immunosuppression were characterized by necrotic areas of variable severity. Although apoptosis has been morphologically defined in opposition to "necrosis" (17), recent observations lead us to consider these two patterns of cell death as part of a continuum. The same death stimuli lead to both necrosis and apoptosis (19), depending on the intensity of the stimulus and the availability of apoptogenic proteases (20). In this study, we addressed the question of whether the extensive cell death leading to necrosis observed in EBV-related PCNSLs involved apoptotic process. The cell's susceptibility to apoptosis was studied by the TUNEL method. Although the number of apoptotic cells tended to be slightly higher for immunocompetent patients, there was no statistical difference between the two groups. When analyzing the edge of necrotic areas by TUNEL, few nuclei were positive, agreeing with the few apoptotic bodies found by electron microscopy. These results suggest that the apoptotic mechanism does not play a major role in the extensive cell death leading necrosis that characterizes EBV-related PCNSLs.

The mechanisms of tissue necrosis and vascular damage in EBV-associated lymphoproliferative disorders are still unknown. Recent works, focusing on the chemokine interferon- $\gamma$-inducible protein-10 and the monokine induced by interferon $\gamma$ expression, suggest that these molecules would be responsible (21). However, the exact role of these molecules has not yet been studied in EBV-related PCNSLs.

High expression of BCL-2-related proteins in numerous systemic lymphomas has been shown previously (12). This could suggest that proteins involved in the control of programmed cell death may also have a role in lymphoma pathogenesis. EBV has been shown to induce, through its latent protein LMP1, upregulation of the antiapoptotic molecule BCL-2 in vitro $(9,10)$. In vivo studies showed a correlation of expression of LMP1 with BCL-2 and BCL-X in human non-Hodgkin's lymphomas (11, 12), whereas all EBV-positive cases were described to be positive for BCL-X in Hodgkin's disease (12). From these observations, it has been suggested that EBV, through transactivation of antiapoptotic proteins, may block apoptosis and then have a role in lymphomagenesis. However, the exact pathologic role of BCL-2-related proteins in human tumors, proteins that are widely expressed in normal tissues $(22,23)$, is still uncertain.

Our observations confirm that PCNSLs related to immunosuppression are characterized by high expression of BCL-2, as compared with PCNSLs unrelated to EBV. BCL-X is a BCL-2 homologue, which in its long form is able to block apoptosis whereas in its short form favors programmed cell death. As demonstrated in systemic lymphomas (12), BCL-X was significantly more highly expressed in EBV-related lymphomas. Although the polyclonal antibodies in use are unable to distinguish between the long and the short forms of BCL-X, previous works showed that the antiapoptotic long form of BCL-X was the most frequently expressed $(8,24)$. MCL-1, widely expressed in both groups of PCNSLs, was shown in vitro to be induced by LMP1 (13) in a transient manner. The 
absence of difference regarding MCL-1 expression in our study is consistent with that found in systemic lymphomas (12) and could perhaps be partly explained by this short-term effect. BAX was expressed in nearly all cases of PCNSLs, whether associated with immunosuppression or not. It is surprising that cases that showed more than $80 \%$ of positive tumor cells $(++)$ were significantly higher in immunosuppressed patients. This contrasts with results in systemic lymphomas (12), but another scale took into account all positive cases.

Another point of interest is the consequence of overexpression of all of these proteins with opposite effects on apoptosis. The antiapoptotic effect of BCL-2 may be balanced by the activity of other molecules that belong to the same family. For example, BCL-2 requires formation of heterodimers with BAX. Thus, the equilibrium between BCL-2: BAX heterodimers (inhibitors of apoptosis) and BAX:BAX (which promotes apoptosis) seems to be important in the regulation of apoptosis. A balance between the activity of different BCL-2 family proteins would determine the cells' susceptibility to apoptosis. Prediction of cellular susceptibility to apoptosis by knowing the relative level of expression of each protein of the BCL-2 family is difficult because the interaction of BCL-2-related proteins is complex and not fully understood. Also, analyzing the levels of expression does not imply analyzing its function. For example, it was recently shown that BCL-2 is able to be cleaved by caspases to a Bax-like death effector (25). Moreover, a recent article (26) described in hematopoietic malignancies that BAX, the main protein of the BCL-2 family that promotes cell death, can display mutations that are associated with a loss of function.

In this study, cells' susceptibility to apoptosis was analyzed using the TUNEL method and no difference between the two groups was found, despite an overexpression of BCL-2, BCL-X, and BAX in immunosuppressed patients. One may hypothesize that BAX expression counteracts the antiapoptotic effect of BCL-2 and BCL-X.

In this article, we have shown that there is no major difference regarding the rate of apoptosis between PCNSLs whether they are related to EBV or not. In contrast, PCNSLs related to EBV are characterized by large areas of necrosis; numerous reactive cells; and overexpression of BCL-2, BCL-X, and $\mathrm{BAX}$ proteins. These findings suggest that upregulation of the BCL-2 family in EBV-related lymphomas is not restricted to antiapoptotic proteins and has no major effects on tumor cells' susceptibility to apoptosis.

Acknowledgments: The authors thank Dr. A. Le Tourneau for her expert knowledge of image analy- sis, Dr. P. Broët for statistical analysis, V. Ducruit and $M$. Candau for their technical assistance, $M$. Wolferberger for photographic assistance, and $T$. Buss for reviewing the manuscript.

\section{REFERENCES}

1. Raphaël M, Gentilhomme O, Tulliez M, Byron P-A, Diebold J, the French Study Group of Pathology for Human Immunodeficiency Virus-Associated Tumors. Histopathologic features of high-grade non-Hodgkin's lymphomas in acquired immunodeficiency syndrome. Arch Pathol Lab Med 1991; 115:15-20.

2. Mac-Mahon EME, Glass JD, Hayward SD, Mann RB, Becker PS, Charache P, et al. Epstein-Barr virus in AIDS-related primary central nervous system lymphoma. Lancet 1991;338: 969-73.

3. Camilleri-Broët S, Davi F, Feuillard J, Seilhean D, Michiels JF, Brousset $\mathrm{P}$, et al. AIDS-related primary brain lymphomas: histologic and immunohistochemical study of 51 cases. Hum Pathol 1997;28:367-74.

4. Geddes JF, Bhattacharjee MB, Savage K, Scaravilli F, McLaughlin JE. Primary cerebral lymphoma: a study of 47 cases probed for Epstein-Barr virus genome. J Clin Pathol 1992;45:587-90.

5. Camilleri-Broët S, Martin A, Moreau A, Gontier MF, Rousselet MC, Caulet Maugendre S, et al. Primary central nervous sytem lymphomas (PCNSLs) in 72 immunocompetent patients: pathological findings and clinical correlations. Am J Clin Pathol 1998;110:607-12.

6. Hockenbery D, Nunez G, Milliman C, Schreiber RD, Korsmeyer SJ. Bcl-2 is an inner mitochondrial membrane protein that blocks programmed cell death. Nature 1990;358:334-6.

7. Oltvai ZN, Milliman CL, Korsmeyer SJ. Bcl-2 heterodimerizes in vivo with a conserved homolog, BAX, that accelerates programmed cell death. Cell 1993;74:609-19.

8. Boise LH, Gonzalez-Garcia M, Postema CE, Ding L, Lindsten T, Turka LA, et al. Bcl-x, a bcl-2-related gene that functions as a dominant regulator of apoptotic cell death. Cell 1993; 74:597-608.

9. Henderson S, Rowe M, Gregory C, Croom-Carter D, Wang F, Longnecker $\mathrm{R}$, et al. Induction of bcl-2 expression by Epstein-Barr virus latent membrane protein 1 protects infected B cells from programmed cell death. Cell 1991;65: 1107-15.

10. Finke J, Frizen R, Ternes P, Trivedi P, Bross KJ, Lange W, et al. Expression of bcl-2 in Burkitt's lymphoma cell lines: induction by latent Epstein-Barr virus genes. Blood 1992;80: 459-69.

11. Camilleri-Broët S, Davi F, Feuillard J, Bourgeois C, Seilhean $\mathrm{D}$, Hauw JJ, et al. High expression of latent membrane protein 1 of Epstein-Barr virus and BCL-2 oncoprotein in acquired immunodeficiency syndrome-related primary brain lymphomas. Blood 1995;88:432-5.

12. Schlaifer D, Krajewski S, Galoin S, Rigal-Huguet F, Laurent G, Massip P, et al. Immunodetection of apoptosis-regulating proteins in lymphomas from patients with and without human immunodeficiency virus infection. Am J Pathol 1996; 149:177-85.

13. Wang S, Rowe M, Lundgren E. Expression of the Epstein Barr virus transforming protein LMP1 causes a rapid and transient stimulation of the Bcl-2 homologue Mcl-1 levels in B-cell lines. Cancer Res 1996;56:4610-3.

14. Harris NL, Jaffe ES, Stein H, Banks PM, Chan JK, Cleary ML, et al. A revised European-American classification of lymphoid neoplasms: a proposal from the international lymphoma study group. Blood 1994;84:1361-92.

15. Hamilton-Dutoit S, Rea D, Raphaël M, Sandvej K, Delecluse 
HJ, Gisselbrecht C, et al. Epstein-Barr virus latent gene expression and tumor cell phenotype in AIDS-related nonHodgkin's lymphoma. Am J Pathol 1993;143:1072-85.

16. Lennert K, Feller A, editors. Histopathology of nonHodgkin's lymphomas. (2nd ed.). New York: Springer-Verlag; 1992.

17. Kerr JFR, Wylie AH, Currie AR. Apoptosis: a basic biological phenomenon with wide-ranging implications in tissue kinetics. Br J Cancer 1972;26:239-57.

18. Coté TR, Manns A, Hardy CR, Yellin FJ, Hartge P, the AIDS/ Cancer Study Group. Epidemiology of brain lymphoma among people with or without acquired immunodeficiency syndrome. J Natl Cancer Inst 1996;88:675-9.

19. Shimizu S, Eguchi Y, Kamiike W, Matsuda H, Tsujimoto Y. Induction of apoptosis as well as necrosis by hypoxia and predominant prevention of apoptosis by bcl-2 and bcl-xl. Cancer Res 1996;56:2161-6.

20. Hirsch T, Marchetti P, Susin SA, Dallaporta B, Zamzami N, Marzo I, et al. The apoptosis-necrosis paradox: apoptogenic proteases activated after mitochondrial permeability transition determine the mode of cell death. Oncogene 1997;15: 1573-81.

21. Teruya-Feldstein J, Jaffe ES, Burd PR, Kanagane H, Kingma DW, Wilson WH, et al. The role of Mig, the monokine induced by interferon- $\gamma$ and IP-10, the interferon- $\gamma$-inducible protein 10, in tissue necrosis and vascular damage associated with Epstein-Barr virus positive lymphoproliferative disease. Blood 1997;90:4099-105.

22. Krajewski S, Krajewska M, Miyashita T, Wang HG, Reed JC. Immunohistochemical determination of in vivo distribution of Bax, a dominant inhibitor of bcl-2. Am J Pathol 1994;145: 1323-35.

23. Krajewski S, Bodrug S, Krajewska M, Shabaik A, Gascoyne R, Berean $\mathrm{K}$, et al. Immunohistochemical analysis of mcl-1 protein in human tissues: differential regulation of mcl-1 and bcl-2 protein production suggests a unique role for mcl-1 in control of programmed cell death in vivo. Am J Pathol 1995;146:1309-19.

24. Xerri L, Parc P, Brousset P, Schlaifer D, Hassoun J, Reed JC, et al. Predominant expression of the long form of BCL-X (BCL-xL) in human lymphomas. Br J Haematol 1996;92: 900-6.

25. Cheng EHY, Kirsch DG, Clem RJ, Ravi R, Kastan MB, Bedi A, et al. Conversion of Bcl-2 to a BAX-like death effector by caspases. Science 1997;278:1966-8.

26. Meijerink JPP, Mensink EJBM, Wang K, Sedlack TW, Slöetjes AW, de Witte T, et al. Hematopoietic malignancies demonstrate loss-of-function mutations of Bax. Blood 1998;91: 2991-7. 